ORIGINAL ARTICLE

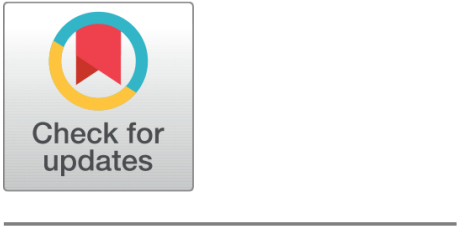

OPEN ACCESS

Received: 29.01 .2020

Accepted: 07.02.2020

Published: 15.02.2020

Editor: Dr. D. R. Galfat

Citation: O' Reilly M, Sheehan E (2020) A national virtual fracture clinic service: A more tactful approach. International Journal of Orthopaedics Traumatology \& Surgical Sciences 6(1): 35-38. https:// doi.org/10.47618/IJOTSS/v6i1.8

* Corresponding author.

marcoreilly@gmail.com

Funding: None

Competing Interests: None

Copyright: (c) 2020 O’ Reilly \& Sheehan. This is an open access article distributed under the terms of the Creative Commons Attribution License, which permits unrestricted use, distribution, and reproduction in any medium, provided the original author and source are credited.

Published By Society of Orthopaedics, Surgical and Dental Sciences

\section{ISSN}

Print: 2455-0809

Electronic: 2454-4167

\title{
A national virtual fracture clinic service: $A$ more tactful approach
}

\author{
Marc O' Reilly ${ }^{*}$, Eoin Sheehan ${ }^{1}$ \\ 1 Department of Trauma and Orthopaedic Surgery, Midlands Regional Hospital Tullamore, \\ Arden Road, Tullamore, Co. Offaly, R35 NY51, Ireland
}

\section{Abstract}

Introduction: The redesign and reconfiguration of the traditional "face to face" fracture clinic model towards virtual assessment and management of patients has been shown to be safe, cost-effective and associated with high patient satisfaction and patient reported outcome rates. The purpose of this study was to look at the potential financial implications of introducing a national virtual fracture clinic service in Ireland. Methods: A combination of established costings for a virtual fracture clinic pathway at our institution and current available public data was utilised to create a national projection. Results: The introduction of a national TAC service could lead to areduction of $31.5 \%$ of patients attending traditional "face to face" fracture clinic appointments with a further $35 \%$ of this cohort being discharged directly representing an overall projected cost saving per annum in excess of €3.3 million. Conclusion: The introduction of a national TAC service would promote patient empowerment without comprising clinical care and could provide significant cost savings and financial benefits for the Irish Public Health System without the need for substantial investment.

Keywords: Trauma Assessment Clinic; virtual fracture clinic; health reform

\section{Introduction}

The virtual clinic model is increasingly being adopted by various medical and surgical specialities and has revealed both a safe and cost-effective patient pathway associated with high patient satisfaction rates and patient reported outcomes. [18] The redesign and reconfiguration of the traditional "face to face" fracture clinic model towards virtual assessment and management of patients has been shown in some studies to equate to a saving of almost $40 \%$ in direct costs. [811] While indirect costs are more difficult to accurately determine, some stud- ies have cited approximately $€ 80$ per consultation as a cost to society, because of a reduction in productivity, as well as equating to nearly half a day of school lost with regard to paediatric fracture clinic appointments. [12-14]

A virtual fracture clinic service, known as the Trauma Assessment Clinic or TAC, was introduced at the Midlands Regional Hospital Tullamore (MRHT) in 2016 and was the first unit to introduce this novel care pathway in the Irish Public Health System. [15] In this model patients arriving to the Emergency Department (ED) with injuries that are TAC appropriate 
(simple, stable fracture patterns)are treated as per a recognised protocol. Patients are provided with information about their injury and placed in a removable splint or cast and informed that they will receive a follow up phone call from the orthopaedic team. Within 24-72 hrs the patient's clinical notes and $\mathrm{x}$-rays are reviewed by the TAC multidisciplinary team (MDT) and patients are contacted and counselled as to their planned treatment. 15 One study revealed that during the first 19 months of its introduction the TAC reviewed a total of 2,704 patients which represented a cost saving of over quarter of a million euro, when compared to the traditional "face to face" pathway, with $97 \%$ of surveyed patients stating they agreed or strongly agreed that they were satisfied with their recovery. [15]

The aim of this study was to look at the potential financial implications of introducing a national virtual fracture clinic service in Ireland.

\section{Methods}

A direct comparison of patient numbers reviewed in the traditional "face to face" fracture clinic, pre and post the introduction of the TAC, was carried out between two corresponding periods. These figures along with established costings of the TAC pathway at MRHT were inputted into current available public data to create a national projection.

\section{Results}

\section{Pre and post TAC introduction comparison:}

During the period of May 2017 to Feb. 2018 [Post TAC] there was a total of 1,832 patients reviewed via the traditional "face to face" fracture clinic at MRHT. During the corresponding period in 2014-2015 [Pre TAC] there was a total of 2,676 patients reviewed via the traditional "face to face" fracture clinic at MRHT. [15] This represents a reduction of 31.5\% following the introduction of the TAC pathway (See Table 1).

Table 1. Comparison of patient numbers reviewed pre and post introduction of TAC

\begin{tabular}{cc}
\hline Time Period & Patient Numbers Reviewed \\
\hline $2014-2015$ & 2676 \\
$2017-2018$ & 1832 \\
Reduction & $31.5 \%$ \\
\hline
\end{tabular}

\section{National Projections}

A cost analysis was performed at MRHT and revealed that a traditional "face to face" fracture clinic appointment costs $€ 129$ versus $€ 28$ for a TAC appointment- a cost saving of $€ 101$ per consultation (See Table 2). [16]
Table 2. Cost comparison of traditional "face to face" clinic and TAC

\begin{tabular}{ll}
\hline Clinic Type & $\begin{array}{l}\text { Cost per consultation } \\
\text { / Patient }\end{array}$ \\
\hline $\begin{array}{l}\text { Traditional "face to } \\
\text { face" fracture clinic }\end{array}$ & $€ 129$ \\
Trauma & $€ 28$ \\
Assessment Clinic \\
(TAC)
\end{tabular}

Currently in Ireland approximately 55,000 new patients attend fracture clinics annually. [17] Based on the MRHT TAC model figures, the introduction of a national TAC service could lead to a reduction of 17,325 [31.5\%] patients attending traditional "face to face" fracture clinic appointments representing a potential cost saving of over $€ 1.7$ million at initial assessment (See Table 3).

Table 3. Initial assessment patient number and cost projections

\begin{tabular}{llll}
\hline $\begin{array}{l}\text { Patient Num- } \\
\text { bers }\end{array}$ & $\begin{array}{l}\text { Traditional } \\
\text { "face to } \\
\text { face" Clinic }\end{array}$ & $\begin{array}{l}\text { Trauma } \\
\text { Assessment } \\
\text { Clinic [TAC] }\end{array}$ & Cost \\
\hline $\begin{array}{l}\text { Pre national } \\
\text { TAC service }\end{array}$ & 55000 & - & $€ 7,095,000$ \\
$\begin{array}{l}\text { Post national } \\
\text { TAC service }\end{array}$ & 37,675 & 17,325 & $€ 5,345,175$ \\
$\begin{array}{l}\text { Potential Cost } \\
\text { Saving at } \\
\text { initial assess- } \\
\text { ment }\end{array}$ & & & $€ 1,749,825$ \\
\hline
\end{tabular}

It is estimated that each new attendance at a traditional "face to face" fracture clinic appointment generates 2.6 return visits. [17] Current data from the MRHT TAC model reveal that $35 \%$ of patients reviewed in the TAC are discharged directly. [15] Therefore of the projected 17,325 patients that would be reviewed in a national TAC service 6,063 patients would be expected to be discharged directly representing a cost saving of over $€ 1.5$ million due to a reduction in unnecessary return appointments (See Figure 1).

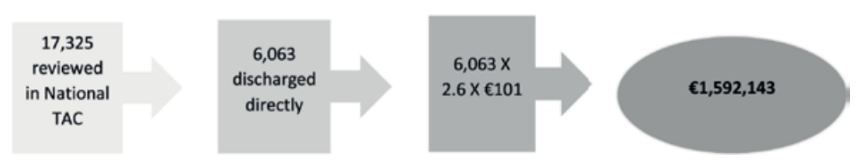

Fig 1. Cost saving from unnecessary return appointments

Therefore, the overall projected cost saving of introducing a national TAC service would be in excess of $€ 3.3$ million per annum (See Table 4). 
Table 4. Total Projected cost saving post national TAC introduction per annum

\begin{tabular}{ll}
\hline Potential cost saving at initial TAC assessment & $€ 1,749,825$ \\
$\begin{array}{l}\text { Potential cost saving due to reduced return } \\
\text { attendances }\end{array}$ & $€ 1,592,143$ \\
$\begin{array}{l}\text { Total Projected Cost Saving Post National TAC } \\
\text { introduction per annum }\end{array}$ & $€ 3,341,968$ \\
\hline
\end{tabular}

\section{Discussion}

A gross under funding of the Irish Public Health service over numerous preceding decades has led to the extreme challenges with regard to patient access, bed availability, staff shortages and waiting lists. [18, 19] From February 2016 to January 2017 there has been an increase of $26 \%$ in orthopaedic outpatient waiting lists with orthopaedics having the highest median patients waiting across all outpatient specialities. [20] Furthermore it is estimated that a third of these listed patients do not need a consultant evaluation and could be dealt with safely via alternative pathways. [20] Any measures that promote patient empowerment but without comprising patient care should be harnessed by health managers. [15]

This study reveals the potential cost savings and financial benefits of introducing a national TAC service. The projected direct cost saving of over $€ 3.3$ million does not take into account the far greater and outreaching economic and societal implications of reduced, unwarranted follow-up in the context of work days lost, school days lost and associated childcare costs. A national roll-out of the TAC service would require little investment as the necessary infrastructure of digital imaging is already in place and not being utilised to it's maximum potential in terms of electronic referral capacity and clinical conferencing. [21,22] Furthermore the necessary collaterals of allied health professionals and administrative staff would only require a reorganisation or redeployment of services in most units.

Additional benefits of the TAC model are the allowance of more time for more complex cases as a result of reduced unnecessary appointments. It also acts as a safety net for any potentially missed fractures but also providing an invaluable teaching platform for undergraduate and higher surgical trainees. [15]

A nationwide virtual fracture clinic pathway is certainly attainable and would provide huge benefits for patients as well as being a world first placing Ireland at the forefront of world leadership in terms of new health care reform.

\section{Conclusion}

The introduction of a national TAC service would promote patient empowerment without comprising clinical care and could provide significant cost savings and financial benefits for the Irish Public Health System without the need for substantial investment.

\section{Compliance with ethical standards}

Conflict of interest: The authors declare that they have no conflict of interest.

Ethics Ethical approval was not required for the study as it was a service evaluation utilizing public available data.

\section{References}

[1] Mark DA, Fitzmaurice GJ, Haughey KA, O'Donnell ME, Harty JC. Assessment of the quality of care and financial impact of a virtual renal clinic compared with the traditional outpatient service model. International Journal of Clinical Practice. 2011;65(10):11001107. Available from: https://dx.doi.org/10.1111/j.1742-1241.2011. 02750.x. doi:10.1111/j.1742-1241.2011.02750.x.

[2] Rathod D, Win T, Pickering S, Austin M. Incorporation of avirtualassessment into a care pathway for initial glaucoma management: feasibility study. Clinical \& Experimental Ophthalmology. 2008;36(6):543546. Available from: https://dx.doi.org/10.1111/j.1442-9071.2008. 01831.x. doi:10.1111/j.1442-9071.2008.01831.x.

[3] Hunter J, Claridge A, James S, Chan D, Stacey B, Stroud M. Improving outpatient services: the Southampton IBD virtual clinic. Postgrad Med J. 1042;88:487-91.

[4] Kotecha A, Bonstein K, Cable R, Cammack J, Clipston J, Foster P. Qualitative investigation of patients' experience of a glaucoma virtual clinic in a specialist ophthalmic hospital in London, UK. BMJ Open. 2015;5(12):e009463-e009463. Available from: https://dx.doi.org/10. 1136/bmjopen-2015-009463. doi:10.1136/bmjopen-2015-009463.

[5] Logishetty K. Adopting and sustaining a Virtual Fracture Clinic model in the District Hospital setting - a quality improvement approach. BMJ Quality Improvement Reports. 2017;6(1):u220211.w7861-u220211.w7861. Available from: https://dx.doi.org/10.1136/bmjquality.u220211.w7861. doi:10.1136/bmjquality.u220211.w7861.

[6] Brogan K, Bellringer S, Akehurst H, Gee C, Ibrahim N, Cassidy L, et al. Virtual fracture clinic management of fifth metatarsal, including Jones', fractures is safe and cost-effective. Injury. 2017;48(4):966970. Available from: https://dx.doi.org/10.1016/j.injury.2017.02.003. doi:10.1016/j.injury.2017.02.003.

[7] Bellringer SF, Brogan K, Cassidy L, Gibbs J. Standardised virtual fracture clinic management of radiographically stable Weber B ankle fractures is safe, cost effective and reproducible. Injury. 2017;48(7):16701673. Available from: https://dx.doi.org/10.1016/j.injury.2017.04.053. doi:10.1016/j.injury.2017.04.053.

[8] Mackenzie SP, Carter TH, Jefferies JG, Wilby JBJ, Hall P, Duckworth $\mathrm{AD}$, et al. Infographic: Trauma Triage Clinic reduces unnecessary fracture clinic attendances and costs with comparable clinical outcomes. The Bone \& Joint Journal. 2018;100-B(7):957-958. Available from: https://dx.doi.org/10.1302/0301-620x.100b7.bjj-2018-0623. doi:10.1302/0301-620x.100b7.bjj-2018-0623.

[9] Anderson GH, Jenkins PJ, McDonald DA, Meer RVD, Morton A, Nugent $\mathrm{M}$, et al. Cost comparison of orthopaedic fracture pathways using discrete event simulation in a Glasgow hospital. BMJ Open. 2017;7(9):e014509-e014509. Available from: https://dx.doi.org/10. 1136/bmjopen-2016-014509. doi:10.1136/bmjopen-2016-014509.

[10] Jenkins PJ, Morton A, Anderson G, Meer RBVD, Rymaszewski LA. Fracture clinic redesign reduces the cost of outpatient orthopaedic trauma care. Bone \& Joint Research. 2016;5(2):33-36. Available from: https://dx.doi.org/10.1302/2046-3758.52.2000506. doi:10.1302/20463758.52.2000506. 
[11] Mckirdy A, Imbuldeniya AM. The clinical and cost effectiveness of a virtual fracture clinic service: An interrupted time series analysis and before-and-after comparison. Bone Joint Res. 2017;6(5):259-69.

[12] Jenkins PJ, Ga, Murray O, Anthony I, Nugent MP, Ireland A. The Glasgow fracture pathway: a virtual clinic. BJJ News. 2014.

[13] Morris MWJ, Bell MJ. The socio-economical impact of paediatric fracture clinic appointments. Injury. 2006;37(5):395-397. Available from: https://dx.doi.org/10.1016/j.injury.2005.12.010. doi:10.1016/j.injury.2005.12.010.

[14] Holm AGV, Lurås $\mathrm{H}$, Randsborg $\mathrm{PH}$. The economic burden of outpatient appointments following paediatric fractures. Injury. 2016;47(7):1410-1413. Available from: https://dx.doi.org/10.1016/j. injury.2016.04.007. doi:10.1016/j.injury.2016.04.007.

[15] Reilly MO, Breathnach O, Conlon B, Kiernan C, Sheehan E. Trauma assessment clinic: Virtually a safe and smarter way of managing trauma care in Ireland. Injury. 2019.

[16] Kiernan CVT, Mcmahon CJ. Analysis of an emergent change model in a complex Irish healthcare system: study of a regional Orthopaedic unit MBA Thesis submission. University College Dublin, Ireland. 2017.

[17] Sheehan E. Trauma Assessment Clinic "working smarter in the fracture clinic" Charter Day; Royal College of Surgeons in Ireland. 2018.
[18] Turner B. Putting Ireland's health spending into perspective. The Lancet. 2018;391:833-837.

[19] Turner B. The new system of health accounts in Ireland: what does it all mean? Irish Journal of Medical Science (1971 -). 2017;186(3):533540. Available from: https://dx.doi.org/10.1007/s11845-016-1519-2. doi:10.1007/s11845-016-1519-2.

[20] O'Reilly MF, Mohamed KM, Sheehan EC. General practitioner attitudes and experiences of orthopaedic services in the Irish midlands. Irish Journal of Medical Science (1971 -). 2019;188(3):735741. Available from: https://dx.doi.org/10.1007/s11845-018-1911-1. doi:10.1007/s11845-018-1911-1.

[21] Breathnach O, O’Reilly M, Morrissey K, Conlon B, Sheehan E. Electronic referrals for virtual fracture clinic service using the National Integrated Medical Imaging System (NIMIS). Irish Journal of Medical Science (1971 -). 2019;188(2):371-377. Available from: https://dx.doi. org/10.1007/s11845-018-1901-3. doi:10.1007/s11845-018-1901-3.

[22] Reilly MFO, Breathnach OP, Mohamed KM, Sheehan EC. The "National Integrated Medical Imaging System" [NIMIS] - friend, not nimesis! Irish Journal of Medical Science (1971 -). 2019;188(2):365369. Available from: https://dx.doi.org/10.1007/s11845-018-1900-4. doi:10.1007/s11845-018-1900-4. 